\title{
Self-regulation in higher education teacher learning
}

\author{
I.M. VAN EEKELEN ${ }^{1}$, H.P.A. BOSHUIZEN ${ }^{2} \&$ J.D. VERMUNT ${ }^{3}$ \\ ${ }^{1}$ Maastricht University, Fazantenlaan 17, 3951 AH Maarn, The Netherlands (E-mail: \\ Ilse.van.eekelen@interstudie.nl); ${ }^{2}$ Open University, The Netherlands; ${ }^{3}$ Leiden University, \\ The Netherlands
}

\begin{abstract}
Various studies have focused on self-regulated student learning. However, little attention has been given to the self-regulation processes in teacher learning. In this study, we focus on the work-related learning processes reported by experienced higher education teachers. The aim of this study was to discover whether teachers actively self-regulate their learning experiences (as their students are expected to do) and to examine how this regulation takes place in the workplace. We tested some generally held assumptions and conceptions regarding teacher learning. Fifteen experienced college teachers, from three different colleges in The Netherlands, participated. Two semi-structured interviews and a (digital) diary study were used as the primary data collection methods. We collected 86 examples of teacher learning episodes. These were analysed using a phenomenographic method. The results show that our teachers' learning experiences are not as self-regulated, planned, reflective, or spiral as some assume. Sometimes, the teachers' learning was planned (self-regulated), but mostly it occurred in a non-linear (both external and self-regulated) or spontaneous (externally regulated) way. We conclude that our teachers do not always self-regulate their learning, but they mostly do self-regulate their teaching practice (with learning as a result).
\end{abstract}

Keywords: diary study, self-regulated learning, teacher learning, teachers' professional development, workplace learning.

\section{Introduction}

Institutes for Higher Education (HE) are increasingly striving for self-regulated student learning. In order to accomplish meaningful learning (as opposed to rote learning), students are supposed to actively self-regulate their learning processes. Furthermore, students are expected to master lifelong learning skills in order to be able to regulate their own learning once they are working in their fields of expertise.

As a result of this changing view with respect to the teaching-learning process (Verloop 2001), the teacher's role is nowadays changing from transmission of knowledge to supporting and guiding self-regulated student learning (Vermunt and Verloop 1999). This requires 
substantially different knowledge and radically different skills than most teachers now have (Darling-Hammond 1997). Therefore, teachers themselves are also expected to self-regulate their learning in order to obtain this knowledge and these skills.

How do HE teachers learn and more specifically how do they self-regulate their learning? Although not many studies deal with self-regulation in HE teacher learning, examples can be found in the field of teacher education (see for example Guilfoyle, Hamilton and Pinnegar 1997; Hamilton 1998; Tillema and Kremer-Hayon 2002). In this field it is recognized that it is important to prepare (student) teachers to develop their future pupils' regulation skills.

Given that we expect students and student teachers to actively self-regulate their learning, we wondered in this study in what way experienced HE teachers themselves actually learn and if and how they self-regulate their learning processes. As a starting point for our study we used the three conceptions of how teachers learn as formulated by Cochran-Smith and Lytle (1999), in order to define the type of learning we wanted to investigate. In the first conception, teacher learning is seen as coming to know what is already known (formal knowledge). In this view, (experienced) teachers learn from best practice examples in the literature, "how to teach" books, or training. In the second conception, teacher learning is seen as constructing practical knowledge by reflecting on experience. Here, it is assumed that teachers learn when they have opportunities to examine and reflect on the knowledge that is implicit in good practice. Learning takes place by consciously reflecting on the flow of classroom action. In the third conception, it is assumed that the knowledge teachers need in order to teach is generated when teachers treat their own classrooms and schools as sites for intentional investigation. The three teacher learning conceptions differ in the way learning is perceived: from a externally directed, passive, and knowledge-consuming process, towards a self-directed, active, and knowledge-creating process. While the first conception is still the basis of many professional development programs, the second and third conceptions relate more closely to the current, constructive view on adult learning. From this perspective, the learner learns from experience or might borrow ideas from others to scaffold the learning. In addition, it is the learner him/herself who is actively forming new knowledge and connecting it to an existing cognitive structure. Therefore, in this study, learning was defined as an experience whereby knowledge, skills, new attitudes related to work are acquired 
and recognized by the teachers themselves. In this study, the acquisition of the new knowledge, skills or attitudes does not imply that the existing knowledge must be replaced by new knowledge. Although we do not exclude these accommodative forms of learning, based on the literature of teachers' beliefs (Pajares 1992; Calderhead 1996), we concur with Hashweh (2003) that teacher learning at the workplace is probably assimilative most of the time.

\section{Teacher workplace learning}

Within our constructive view on adult workplace learning, there are three perspectives on learning at the workplace, which provide a theoretical framework for this study.

First, within adult learning, self-directed learning (SDL) is seen as representing the mode of learning characteristic of adulthood (Candy 1991). It has been defined by Long (1994, p. 14) as

"the learner's psychological processes that are purposively and consciously controlled, or directed for the purpose of gaining knowledge and understanding, solving problems and developing or strengthening a skill”".

The SDL is often associated with setting goals, selecting learning resources, and managing time. Together, these characteristics suggest that self-directed learners reflect, assess, and evaluate rather than uncritically accept and internalise information (Confessore and Kops 1998). Moreover, self-directed learners are responsible for most of the detailed decision-making about learning, including choices about what and how to learn and at what pace the learning will occur (Tough 1979).

Second, experiential learning has a prominent place in most of the literature on adult education (Kwakman 1999). Experiential learning offers an integrative perspective on learning and combines experience, perception, cognition, and behaviour (Kolb 1984). Although there is not much empirical evidence to support the Kolb model, it is frequently used in adult education and in-company training (Bolhuis and Simons 1999). The description of experiential learning emphasizes an active role of the learner and several phases in the learning process. The learner experiences, reflects, conceptualises, and experiments, and starts experiencing again. Experiential learning assumes that the end of a learning process is the beginning of a new learning process. It is a spiral model 
that aims at the improvement of the ongoing process of professional development.

Third, much attention is given to the reflection process in adult/ teacher learning. The notion of reflection as a way in which teachers learn has become something of a buzzword in education (Francis 1995; Tillema 2000). Most of the existing general research elaborates or tests the reflection-in/on-action model developed by Schön (1987). The ALACT model (Korthagen and Kessels 1999) specifies five phases of teacher reflection on action: action, looking back, awareness of essential aspects, creating alternative methods of action, and trial. Like the experiential learning spiral, the ALACT model assumes that learning can be more or less planned or predicted by following the spiral. Also like the experiential learning spiral, a behaviour change (experiment or action) is a necessary part of the learning process.

The examination of self-directed learning and the views of experiential and reflective learning reveal (at least) five theoretical assumptions which might underlie self-regulated learning at the workplace. These assumptions 'predict' how learning processes (should!) take place. First, it is assumed that workplace learning should be a self-directed and active process. Second, it has the characteristics of a 'purposively and consciously controlled' planned process. Third, learning is represented as spiral. It is assumed that the end of a learning process is also the beginning of a new learning process. Fourth, reflection as an important phase in the learning process is emphasized. Finally, since the learning and reflection cycles include "action", the fifth assumption is that all learning should involve an (observable) behavioural change or experiment.

However, some authors have come to different conclusions about self-regulated learning at the workplace based on empirical evidence. For example, Candy (1991), Eraut et al. (1998), and Kwakman (1999) acknowledge the unconscious character of work-related learning processes. First, according to them, most adult learners are not aware of themselves in the role of learner. Second, serendipity plays an important role in determining the direction that many learning projects take. Third, much learning arises from and seeks to resolve a specific problem situation. Fourth, very few learning endeavors are entirely self-regulated, but instead depend on individual motives and interests shaped by interaction with other people. Fifth and finally, self-regulated learning is rarely completely solitary. Clearly, according to these authors, the self-regulated learning process at the workplace is complex and unpredictable, and unfolds as it goes along. 


\section{Student self-regulated learning}

The construct of self-regulated workplace learning becomes even more complex when we take into account the perspective of self-regulation in student learning. We consider this an important area for our study given that, as said in the introduction, HE teachers are expected to foster student self-regulated learning and thus we might expect them to practice it themselves as well.

In the last two decades, the characteristics of the students' self-regulation processes have become more clear (Shuell 1988; Simons 1993; Garcia 1999). Zimmerman (2002) provides the latest overview. He presents (p. 66) eight skills which are important to these processes (without necessarily being used all the time). These skills include: (1) setting specific proximal goals for oneself, (2) adopting powerful strategies for attaining these goals, (3) monitoring one's performance, (4) restructuring one's learning environment to make it compatible with one's goals, (5) managing one's time effectively, (6) self-evaluating one's methods, (7) attributing results to causation, and (8) adapting future methods. The overview of Zimmerman implies that self-regulated learners should not only have the ability to prepare and take the necessary steps in order to learn, but also have to take care of their own monitoring, motivation and feedback process during and after learning. The entirety of all these steps is called learning functions (Van Hout-Wolters et al. 2000), or learning activities (Vermunt and Verloop 1999). Several authors have made overviews of the (micro) activities a student should undertake in order to learn (e.g. Pintrich 1994; Vermunt and Verloop 1999). Most of them (see also Winne and Perry 2000) make a distinction between cognitive, affective or motivational, and meta-cognitive learning functions.

However, as in the field of workplace learning (see above), some studies show that not all students seem to be capable of self-regulated learning. Vermunt $(1996,1998)$ found four qualitatively different (student) learning patterns in which the regulation and the strategies of learning differ. Within these four patterns, Vermunt distinguished four regulation types: (1) an experienced lack of regulation, (2) mostly external regulation, (3) self-regulation of one's own learning process, and (4) both external and self-regulation. The study of Oosterheert and Vermunt (2001) in a teacher education context showed similar results. They describe five 'orientations to learning to teach', which differentiate between an external, or self-regulated knowledge construction and performance improvement. Only a minority of the student teachers appeared to be fully self-regulated in both these processes. 


\section{Self-regulated teacher learning}

To conclude, by trying to define the concept of self-regulated teacher learning, it appears that over the past 30 years definitions of SRL have become increasingly encompassing (Paris and Paris 2001). Zimmerman and Schunk (2001) even identified seven different theoretical views on SRL. Their definition of SRL has often cited: "SRL encompasses the degree that students are meta-cognitively, motivationally and behaviourally active participants in their own learning process" (2001, p. 5). According to Zimmerman and Schunk (2001) SRL refers to self-generated thoughts, feelings and behaviours that are oriented to attaining learning goals. Based on the five theoretical assumptions underlying adult workplace learning and the student SRL perspective (see the two foregoing sections), we think that the core of self-regulated teacher learning is that the teacher independently and consciously directs the process of attaining learning goals. The degree to which a teacher is able to do so makes the teacher more or less a self-regulated learner.

\section{Research questions}

In order to discover more about self-regulated teacher learning processes and to test our assumptions about teacher workplace learning, the present study focused on the issues of the degree to which teachers actively self-regulate their learning and the ways in which they do so. To answer these questions, we went back to the micro level. We took a closer look at the work-related learning processes reported by experienced HE teachers. The main goal was to empirically characterize the learning events of these teachers. To accomplish this, the following specific research questions were formulated:

- From what activities do HE teachers learn?

- With whom do HE teachers learn?

- How do HE teachers regulate their learning?

- What are the outcomes of HE teacher learning?

- What factors in HE teachers' environments stimulate or inhibit their learning?

\section{Method}

Given the difficulty of eliciting answers to questions about workplace-related learning (mostly informal), we examined two 
approaches used in previous studies in and outside educational settings. Kwakman (1999) collected a range of professional (routine) activities of secondary education teachers in which learning could evolve. She conducted a survey to determine how frequently teachers performed these activities. The disadvantage of this method was the exclusion of nonroutine working/learning activities.

Eraut et al. (1998) adopted another approach. They studied the ways in which business, engineering, and healthcare professionals learn. They used an interview approach, in which almost all participants agreed to do two interviews. In the first interview, questions were asked about the nature of the job, the nature of the competence required to do it, and how these competencies were acquired. The second interview focused on elaborating on the first interview and on factors affecting the amount and direction of learning. Eraut et al. (1998) indicate one important limitation of this approach: it was hard to elicit evidence for learning processes that, if not entirely tacit, do not readily come to mind.

To overcome the limitations of both the foregoing studies, we developed an alternative way to investigate work-related learning events, which included not only two interviews but also the keeping of an electronic diary. Within this descriptive qualitative approach, we used a phenomenographic method to analyse our data (see next section).

\section{Participants}

Fifteen experienced teachers from three different colleges participated in this study. Each college awards a different Bachelor's degree; Information Technology (Language), Teacher Education, or Facility Management. The institutes were chosen on the basis of two criteria:

- at the time they were involved in changing their programs or teaching concepts (in order to ensure that the teachers would be in a changing environment, making it adaptive to learn);

- they had contrasting degree areas (for different kinds of teachers).

The heads of the institutes were asked to provide a list of all teachers with more than 5 years teaching experience and a minimum contract of 0.8 Full Time Equivalent (almost fulltime teachers). From this list, a random shortlist was made with 10 prospective participants. The head of each institute then asked the first five prospective candidates named on the list to participate. Only at the institute for language teacher education was it necessary to ask more than the first five. The main 
reason for refusing to participate was the amount of time involved in participating in the research. In the end, 15 teachers with an average age of 45 years and an average of 17 years of teaching experience participated in the study.

\section{Materials}

Two semi-structured interviews and a diary study were used as the primary data collection methods. In the first interview, the teachers were asked to give examples of situations or activities from which they had learned something. These examples were explored using the five main research questions. Next, the teachers were asked how they would define learning and what learning goals (if any) they had for the following two months. The last question in the interview was about factors that stimulated or inhibited their learning in general. Second, the teachers were asked to keep a diary three times a week (during 1 month) by answering e-mails from the researchers. The e-mail received by the teachers listed the five main research questions. Third, in the final interview, the teacher and one of the researchers looked back upon the e-mails to summarize the way in which the teacher learned, to check interpretations, to discuss recurrent patterns in this learning if there were any, and to determine the degree of the teachers' satisfaction with this learning.

\section{Procedure}

At the start of the first interview, the interviewer explained the goal of the interview: to get an impression of what and how the teacher learned and the factors affecting his or her learning. The interview scheme described above was then followed. At the end of the first interview, the interviewer explained the process of the diary studies. Each interview took between an hour and an hour and a half. All first interviews were tape-recorded and transcribed verbatim.

Next, the teachers were requested to keep an electronic diary for a period of 4 weeks. During this period, they were to report to the researchers three times a week. In order to increase the chance that all teachers would make their diary entries regularly, they were asked to e-mail their diaries. To help the teachers with this task, each teacher received an e-mail from the first author on the (in the first interview) 
agreed 3 days of the week. The teacher was asked to fill in the diary and reply mail at the end of the day. We did not respond to the e-mails, except to give an occasional word of encouragement to the entire group of teachers at the end of some weeks. Three teachers did not respond for a week. They were asked to give a reason (lack of time, sick) and they got back into the rhythm the following week. Six teachers did write in the diary six times or more (half of what was asked of them). The reason for this was mostly "no time to write" and, rarely, "I learned nothing".

Prior to the second interview, each teacher was asked to read through all their own e-mails. We also read the transcripts of the first interviews and all the e-mails. This reading provided us with questions for each participant for clarifications, checking of interpretations and confrontations. We asked, for example, "I see that you haven't reported any learning situations about the object of your field of study. Do you recognize that? How come?" The average length of the second interview was one hour. All second interviews were tape-recorded and transcribed verbatim.

\section{Data analysis}

A phenomenographic research methodology was used for the analysis (Marton 1986, 1990). In this methodology, the researcher describes the qualitative differences in the ways people perceive and conceptualise a phenomenon in conceptual categories. The central phenomenon in this study was "the learning experiences of HE teachers". The data analysis started with a reading of all the material (both interviews and all e-mails). Next, all the e-mails were read again and, based on all learning episodes as reported in the e-mails and the (comments in the) interviews a summary was made for each teacher. The summary included all the answers to the five research questions. Another summary was made for each research question separately. These summaries were read again to develop initial categories of potential conceptualisation related to each of our five research questions (themes); from what activities do teachers learn, with whom, their way of regulation of learning, the learning outcomes and factors that stimulate or inhibit teachers' learning. Within these five themes, the initial categories were developed by grouping similar answers/citations into a (broader) category.

The next step was testing these initial categories within each theme by going back to the summaries and matching all the answers/citations to a 
category. If not all answers/ citations could be matched with the initial categories, a new category was developed or initial categories were changed. Also it could happen that a category was identified while working on a categorization for another theme. The newly identified categories were again tested in the summaries. The reading, categorizing, testing, and recategorising process for each theme was repeated several times until all diversity in the summaries seemed to be covered, in other words until 'saturation' occurred. After reaching this stable grouping in the categorical system, ultimate descriptional categories for each theme were formulated, representing the essential characteristics of the groupings that were found. Each category was illustrated with typical statements. In addition, the decision rules for assigning quotations to a category of description within each theme were formulated. These rules describe the conditions under which quotations were labelled with a certain category.

As the final step in the analysis, for each teacher we looked, based on the decision rules, for the category or categories in which their learning incidents as reported in the e-mails $(N=86)$ would fit (which category matched which teacher?). This procedure resembles the procedure described by Marton (1986, p. 34). "Each quote had two contexts in relation to which it had been interpreted; first the interview [learning incident] from which it was taken, and second the pool of meanings to which it belongs". Sometimes, a quote matched several of our five themes. In this case, the quote was copied several times and put into the categories of each theme in which it fitted.

\section{Results}

\section{How do teachers learn?}

The first research question concerned the activities from which the teachers learned. While analysing the interviews and e-mails, four categories were defined (see Table 1). As has already been said, some quotes matched two pools of meaning. As a result, the total number of frequencies is higher than the total sum of learning incidents $(N=86)$ as reported in the e-mails. Each category is illustrated with a quote and a code between brackets. This code refers to an abbreviation of the institute: Information Technology (IT), Teacher Education (TE), Facility Management (FM), and the identification number of the teacher. 
Table 1. Teacher learning strategies and the frequencies with which they occurred in the e-mails

\begin{tabular}{|c|c|}
\hline Teacher learning strategy & Frequency \\
\hline \multicolumn{2}{|l|}{ 1. Learning by doing } \\
\hline $\begin{array}{l}\text { The teacher learns by doing a task (mostly) alone. This involves figuring } \\
\text { something out by trial and error, for example, a formula, an ICT } \\
\text { application, preparing a class, writing a paper, or correcting homework. } \\
\text { "I was translating a paper about constructive learning. While doing that, I } \\
\text { compared my learning to student learning. I saw a lot of similarities" } \\
(\text { TE5). }\end{array}$ & 19 \\
\hline \multicolumn{2}{|l|}{ 2. Learning in interaction } \\
\hline $\begin{array}{l}\text { A. The teacher learns in interaction with students, both in and outside } \\
\text { classroom situations. For example, a student explains to a teacher how } \\
\text { something works, something unexpected happens in a classroom } \\
\text { situation, or the teacher gains an insight. "Today, during practical work, } \\
\text { I asked the students if they knew how I should download MP3 files from } \\
\text { the Internet. They had wonderful ideas" (IT3). }\end{array}$ & 24 \\
\hline $\begin{array}{l}\text { B. The teacher learns in an (mostly) informal, unplanned interaction with } \\
\text { a colleague. For example, answering e-mails from colleagues, asking } \\
\text { colleagues for opinions or explanations, having a chat at the coffee } \\
\text { machine, or attending a colleague's lesson. "I was writing a paper and all of } \\
\text { a sudden I understood, thanks to a short explanation from a colleague, what } \\
\text { ICT tools I don't understand and should work on" (TE4). }\end{array}$ & 20 \\
\hline $\begin{array}{l}\text { C. The teacher learns by participating in a (mostly) formal or planned } \\
\text { meeting with several colleagues or external experts. This includes training, } \\
\text { meetings, supervision, conferences, etc. "Today, I was in a meeting with my } \\
\text { colleague coaches from the institute. I learned two things: first, my opinion } \\
\text { matters and is shared by others, and second, I should state my opinion in a } \\
\text { more relaxed way and present it with humor" (TE4). }\end{array}$ & 27 \\
\hline 3. Learning by reading (a newspaper, a book, an article) & \\
\hline $\begin{array}{l}\text { The teacher learns by self-study. "Today, I read the biography of Niels } \\
\text { Bohr. It made me think about the individual teaching styles (ITS) of } \\
\text { teachers (FM5). }\end{array}$ & 6 \\
\hline 4. Learning by thinking & \\
\hline $\begin{array}{l}\text { The teacher takes time to reflect and think about school matters while } \\
\text { doing something else (working in the house, driving from house to school, } \\
\text { trying to sleep, etc.) "While doing the laundry, I was thinking about our } \\
\text { Introduction Camp. First about the camp and making pictures, then making } \\
\text { a video and, all of a sudden, I thought about a multimedia cd-rom" (IT3). }\end{array}$ & 3 \\
\hline
\end{tabular}


Of all learning activities, learning by reading and thinking were reported least in our e-mails. Learning in interaction was reported most frequently, followed by learning by doing. While the importance of interaction was very clear in our study (see next section), the role of conscious and structured reflection as supposed by most reflection theories was not so clear. For example, only one teacher mentioned learning by supervision, planned ways of collegial consultation were not mentioned at all. Some teachers used the process of writing a diary as a way to reflect, while others disliked it. One teacher wrote: "I realize with pleasure that, as with supervision, to be forced to reflect works very well" (TE2), while another teacher took an opposite position about the writing in the dairy, "You have to reflect, you have to think, and that's something I don't like. I try to avoid that. I don't have time for it. That means that I find other things more important than thinking about myself, about my own learning" (IT2).

With whom do teachers learn?

The interaction category was divided into three main parts: interaction with students, informal interaction with colleagues, and formal interaction in meetings. Our teachers learned most frequently from colleagues or experts in formal meetings. They mentioned students and informal talks with colleagues less often as learning situations.

Most of our teachers were enthusiastic about their meetings with students who were interns. The meetings with those students and external tutors were very worthwhile for them. "This morning, I visited an intern. Her mentor at that company said something about 'the three functions of Huben'. After our conversation, I asked her what she meant (..). In this kind of conversation, I check my own knowledge: I read this ... is that right ... are you also busy with..." (FM3).

Only one teacher gave an example in which the manager played a role in the learning. When asked about this, most of the teachers said that it was not necessary. "I haven't spoken with my manager in the past month. In my profession, my subject, I cannot learn from him. I also don't have a need for it. He has to manage the big picture and shouldn't interfere with my learning. He influences our learning indirectly by initiating change programs in our institution in which we have to participate" (FM5). With this, we answered our second research question. 
How do teachers regulate their learning?

The third research question concerned the way teachers self-regulate their learning. Based on our data, three different types of regulation can be distinguished: spontaneous learning, non-linear learning, and planned learning (see Table 2).

About two thirds of the learning situations mentioned in the e-mails were unplanned (spontaneous and non-linear). While analyzing the teachers' remarks about setting goals, we noticed that these confirmed this unplanned character of our teachers' learning processes. In the first interview, the teachers were asked to mention learning goals or things they would like to improve upon. Very few teachers reported learning activities in relation to these learning goals in their e-mails. One teacher, when asked about this unplanned learning pattern, said, "That's right. I constantly ask my students to set learning goals and I also ask them to reflect on them in their reports. But I don't do it myself! This is quite an insight!" (FM2).

Another teacher said, "I have a general idea of what I want to learn. While I'm working on that, I encounter problems that make it clearer to me what I want to learn. In this way, I also encounter other things which are much more fun to learn. As a result, I quit the original things" (IT3).

In sum, one third of the learning experiences mentioned in our study were planned. In the rest of the situations, learning took place without planning as a result of an external or problem based type of regulation. With this, the third research question was answered.

\section{The result of learning}

The fourth research question dealt with the issue of whether teacher learning involves a behavioural change. The data was processed in order to discover whether the teachers reported "a behaviour change" or "getting an insight". Four categories could be distinguished (see Table 3).

The first two categories can be characterized as "getting an insight"; the last two as types of "behaviour change". Most learning situations that were reported by the teachers in this study concerned the two "insight" categories. In these categories, there was no sign (yet) that a new behaviour had been developed. When asked about this pattern, one teacher said, "We only reached the step of consciousness, of talking about it and telling each other how bad we are, but that's it. We reach the stage 
Table 2. Three different types of teacher regulation in learning and their frequencies

Three types of teacher regulation
1. Spontaneous learning (external regulation)
An external event or person regulates the learning; the learner does not
actively influence learning. It appears that, all of a sudden, the learner
learns something. After the event, the learner knows what was learned
(learning result) and can (usually) define how it was learned (learning
route). Many of these learning experiences take place after or during a
(formal) meeting/conversation. Often, the object of learning differs
from the goal of the meeting and is not foreseen. "Learning is like a
flashlight. (...) Most of what I learn is spontaneous: usually from a
remark of a colleague or student" (FM2). "I never plan learning; it's
always reactive" (TE5).

2. Non-linear learning (external/ self-regulation)

This form of learning is the (unexpected) result of actively doing something: performing a task or solving a problem. The problem or task emanates from an external factor and the learner him/herself decides to work on it. This means that learning is regulated both externally and internally. The learner does not know beforehand what (no learning goal) and how (no learning route) is going to be learned. Although the learner does not define a learning goal, there is a "working" goal (to solve the problem, to do my task). "I consciously solve problems. The learning that occurs as a result is unexpected (IT5)'.' Non-linear learning can be compared to learning from surfing on the internet. One often starts with a question but, while surfing, one may end up with a completely different insight.

3. Planned learning (self-regulation)

The learner knows beforehand what and how one is going to learn. The learning is self-regulated. The learner creates his/hers own learning activity; not only the learning goal, but also the learning route is known beforehand. The learner consciously tries a different behavior, skill, something which he/she has not tried before, for the sake of mastering that behavior or skill (instead of for the sake of solving a problem). The learner may also plan a conversation with someone else in order to ask for help or direction. "I have things learning goals - in my head which make me more alert to possibilities in my surroundings, a kind of selective perception (FM3)'. "Every chance I get, I try to work on a ([learning] goal”" (TE2). "Learning to use ICT tools is planned; I make time for that in the evenings" (IT4). 
Table 3. Outcomes of learning and their frequencies

Outcome of learning
1. Collecting (professional) knowledge
The outcome of this learning process can be defined as knowing a fact or
gaining a theoretical or practical insight. Unlike in the following category,
the learning process does not necessarily result in a resolution. Reading an
article, figuring out a theory, getting an explanation, or gaining insight are
all examples of the category "collecting knowledge". "Today I read an
article about something I have to teach next semester. Now I know more
about the subject" (FM5).

2. Making a resolution for the next time

The outcome of this learning process is a resolution for the next time the 12 teacher encounters the same type of situation. The teacher decides to (1) repeat the same behavior next time because it appeared to be efficient this time or (2) act differently next time because the current behavior proves to be inefficient. Characteristic of this type of learning (as compared to the last two categories) is that the teacher does not seem to carry out this resolution (at short notice). "I was teaching students a new software program. Although it was not meant to be so, the class became a real chaotic mess. Each student went his own way while discovering the program. I learned that it is much more efficient to allow students to explore an application by themselves, instead of giving them direct instruction. They worked in parallel and learned from each other" (IT3). "I learned today that from now on, I will be very strict about the headlines I set for school papers. I granted one student extension an extension to deadline after which all the students came and made similiar requests .... Give them an inch and they'll take a mile!"' (FM5).

3. Changing social behavior

This category is scored when a teacher is consciously trying a new type of social behavior as a result of a prior experience. During that prior experience, a resolution is made to do it differently next time. "The situation occurred and instantly I thought, this time I'll do it differently: I will tell her very clearly that I can't make the reports anymore. And so I did. She agreed immediately!" (FM3).

4. Performing a new technical skill

This category is scored when a teacher learns to cope with new techniques, systems, or applications. "I was busy putting the grades into the system. While doing this, I thought, well, let's try to put these grades on the intranet as well, and, with help of a colleague, I did" (IT6). 
of confession and God may do the rest. (...) As a result, I can learn something ten times and do it wrong the same number of times" (TE5). "I also make the same mistake more than once. I think it is a habit. I also don't really think beforehand, 'Let's do it differently'. Apparently, a situation triggers a certain reaction. (...) Becoming conscious is only the first step. It does not guarantee a change of behavior" (FM2).

We let the teachers themselves judge whether they had learned anything. According to them, they had learned. However, the learning of most of our teachers did not appear to be spiral. They only appeared to go through one, two or three phases of the experiential learning cycle. Most of our teachers seldom actively searched for or created situations in which they could test their resolutions. According to the learning and reflection cycle (see "Introduction"), this is what they should do in order to learn. A few teachers did finish these cycles. They reported the next step: actively trying the resolution in a new setting. Three out of the fifteen teachers reported the third category more than once (changing social behavior). As might be expected, the group of IT teachers often reported learning situations matching the 'performing a new technical skill' category.

\section{What factors stimulate or inhibit learning?}

The last theme we investigated concerned the factors that stimulate or inhibit teacher learning. Two teachers were completely satisfied with their learning during the research period. More than half of the teachers were not at all satisfied with their learning. As a result, the total list of stimulating and inhibiting factors was long.

"No Time" appeared to be the most inhibiting factor. Most of our teachers complained about their work load. "My day is filled with meetings. I go from one meeting to the next. I'm a teacher! There are days that I don't even turn on my computer and, as a result, I do the work at home at night" (IT5). On the other hand, some teachers did not see this as an inhibiting factor: "I don't have the feeling that I have too little time for my own learning. It just depends on the amount of time I make for it" (IT3).

Some teachers did not feel motivated to learn from or in their work. "I give myself assignments in my private life. Here at the institute, I only have organizational assignments. Those are not very inspiring" $(X)^{1}$. "I learn so much more outside my work that I wonder why I still do this work” (X). " Right now, I'm such an expert in my field that I'm crossing 
the goals of the institute. I can't expect students to learn everything I know. (...). But why should I learn when I can't pass it on to the students anymore (...)? I also don't have a sparring partner at the Institute. I find that difficult" $(X)$.

The autonomous position of our teachers is another inhibiting factor: no demands are made of them and they are not corrected at work. "One of my learning goals is to be a better coach: to guide instead of teach students. But the more I explain to the student, the happier he is. I am rewarded for the opposite behaviour! And nobody sees it. If somebody was sitting next to me, I would not act this way, but nobody corrects me", (FM2).

As a stimulating factor, many of our teachers said that they learned a lot from interns or from students' final projects. Apparently, those external contacts are important for teacher learning. "I learn a lot from external people. For example, I am visiting an intern and when I talk with the intern's tutor or when I speak with people whom I know are experts in my field (FM5).

The results confronted us with something of a puzzle. We could not elicit a clear picture of the factors: there were so many and some were even contradictory. For instance, the factor of room/office-mates. One teacher liked sharing an office in order to ask a colleague questions, the other would rather have an office for oneself in order to have a quiet environment. Thus, some factors were mentioned as both stimulating and inhibiting. Apparently, the factors are very individually based. A previous study done by Kwakman (1999) might offer an explanation for this phenomenon. Kwakman concluded that teachers perceive the task and work environment very subjectively and that these differences in perception are caused by the differences between individual teachers.

\section{Conclusions and discussion}

In this study we raised the question of whether and how teachers self-regulate their learning. Due to the limited number of learning experiences reported, the use of self-reported data, and the absence of observational data in our study, it is difficult to generalize the results. Furthermore, with respect to the influence of the research on the teacher learning process, it must be said that all teachers reported that the study itself influenced their learning. All said that they were more conscious of their learning than normally. However, they also stated that their ways of learning (in terms of their learning activities, with 
whom, planned or not) were not influenced. According to the teachers, they were doing their job as usual, but they noticed more easily when a learning situation occurred. Finally, we do not claim to study "what there is in the world' (reality) but we do claim to study 'what there is in people's conceptions of the world'. By adopting a phenomenographic approach we have studied the perception of teachers about their learning. The benefit of this approach is that these conceptions, which are identified in the context of this particular study, are related to each other in a structure of categories such that, in the words of Renstrom, Andersson and Marton (1990), "the relations between the categories are of a logical character, and the categories have been ordered into a hierarchy in terms of inclusiveness [in which] they are progressively differentiated and integrated". These categories may indicate several patterns which might direct future studies in order to 'decontextualize' our findings.

In the section on teacher workplace learning, we listed five assumptions about learning. In short, learning is ideally a (1) self-regulated, (2) planned, (3) spiral, (4) reflective process and (5) involves a behavioural change. We will start by determining whether these assumptions were confirmed in this study.

Based on the reported learning episodes, three types of regulation could be discerned: external regulation, both external and self-regulation, and self-regulation. Nevertheless, we acknowledge the fact that our teachers' learning experiences are never completely self- or externally regulated. When a learner decides to learn something (self-regulation), this is usually because something in the environment triggers it or leads the way (see also Candy 1991, Bolhuis 2001). Nonetheless, when something in the environment triggers the learning (externally regulated), this is because the learner decides to pay attention to that something. For instance, during a meeting with two graduating students, one of our teachers got a sudden insight into the way a certain subject should be taught. The teacher got this insight because one of the students stated the solution almost literally. The other teacher who was at the meeting did not pay attention to the student's remark because that teacher did not have to teach that subject. So, although this learning experience was defined as externally regulated, the learner still had an role in it by recognizing it as an important remark. With this we underline the view of Oosterheert and Vermunt (2003), who conclude that learning can only occur - ultimately - under the internal control of the learner.

According to the participating teachers, most of their learning situations were unplanned (see Assumption 2). These were called 
spontaneous or non-linear learning experiences. These findings are in line with other studies on teacher learning. For example, the study on the learning process of high school teachers (Kwakman 1999) showed that most learning is not goal-directed but the result of working activities or situations. Others have also found that adult learners rarely preplan their learning. They have reported that adults' learning activities more often than not arose out of some "triggering event" (Spear and Mocker 1984). More specifically, Danes and Tremplay (1985) found that the learning experience does not conform to either a linear or a spiral sequence. The present study also confirms the findings of Oosterheert et al. (2002) concerning student teachers' learning. They found two types of learning activities and regulation: active, intentional learning versus reactive, non-intentional learning. We support their assumptions that, besides deliberate processing, spontaneous insights also play an important role in learning. Apparently, the learning experiences of this particular (and small) group are not always as planned and consciously controlled as described by the experiential and reflective spirals we referred to in the introduction. Rather, they appear to be spontaneous and non-linear learning forms.

As a consequence of the unplanned and unstructured character of most learning experiences of our teachers, we also conclude that learning experiences, like the ones of our teachers, might not (always) be spiral (see Assumption 3). Schön (1987) explains this conclusion as follows. Teachers are not instrumental problem solvers who select the technical means best suited to particular purposes. In many cases, a teacher has to improvise. Most situations are unique, and, accordingly, most solutions to these situations differ. This has an important impact on learning. Because of this non-technical rationality of work, it may be difficult to approach learning from the technical perspective prescribed by experiential and reflective models. In most teacher learning situations in this study, our teachers did not recognized a short-term possibility to test a new solution or behaviour (and thus continue with the last and first step of the cycle). If the opportunity had arisen, it might have been unexpected (and thus the teacher may have been unprepared) or slightly different (and thus have required a different approach). An exception to this conclusion is made for the IT teachers in this study. While exploring a new IT program, they went through the experiential learning cycle several times.

From what activities do teachers who participated in our study learn? This question relates to the fourth assumption about the role of reflection in the learning process. Four categories were distinguished. Of 
all the learning activities, learning by reading and thinking were reported least. Learning in interaction was reported most frequently, followed by learning by doing. While many authors (see "Introduction") emphasize the importance of reflection, this emphasis was not found in our empirical data. All our teachers looked back upon their experiences. In this sense, they reflected. However, very few of the teachers reported a planned or structured form of reflection, such as the ALACT model (Korthagen and Kessels 1999) presented in the introduction. Some teachers even disliked the idea of reflection. And because of the apparently non-spiral character of most learning experiences, (often) nothing was done with these reflective thoughts. Similar findings were reported by Knight (2002) and Kwakman (1999). According to Knight, reflection is not a sufficient condition for learning, because "any kind of thinking of one's practice tends to get described as reflection" (p. 293). Kwakman concluded that reflection only seems to appear in coaching situations, where it is more or less organized. This might suggests that teachers, like students, need guided and sustained opportunities to reflect on their practice, and to consider and try alternatives.

While investigating the outcomes of the teacher learning experiences (see Assumption 5), it was noticed that most learning experiences resulted in 'obtaining professional knowledge' or 'making a resolution for the next time'. Surely, not all the reported learning episodes resulted in a behavioural change (during our study). Nonetheless, the teachers concluded that all these episodes resulted in learning. This finding might be influenced by the way we defined learning (see "Introduction"). In this study, we were satisfied with assimilative learning processes in which the existing knowledge structure does not need to alter fundamentally.

Placing these findings (concerning the five assumptions) in the context of the student self-regulated learning literature we referred to in the introduction, the following conclusions can be drawn. Like students, our teachers seemed to differ in their abilities to self-regulate their learning. Only some of them used some of the skills identified by Zimmerman (2002, see Introduction). For instance, some teachers had difficulty with formulating their learning goals for the coming month. "I never plan learning; it is always reactive". Others did not plan their learning, but did solve consciously their problems: "I consciously solve problems, the learning that occurs as a result is unexpected".

Like students, not all teachers in our population showed the ability to actively and consciously self-regulate their learning experiences. But 
all teachers were involved in spontaneous and non-linear learning. The teachers in our sample, who involved in spontaneous or non-linear learning, maybe were not self-regulating their learning, but our findings indicate that they did self-regulate their teaching practices. That is, they reported (see also Table 1, teacher learning strategy) that they constructed instructional strategies based on specific goals for their students, they enacted them in their classrooms, they monitored the outcomes, they solved problems and they made resolutions in order to revise instruction accordingly. The same argument (teachers self-regulating their teaching practice) is made by Butler (2003). Butler (2003, p. 5) states that "when professional development is situated in practice, teachers actively construct approaches to teaching (...), and when they focus on their own learning in that context (with opportunities for goal setting, active learning, reflection and selfassessment), they simultaneously revise knowledge about learning and teaching". We therefore want to add something to our definition of SRL (see "Introduction"). We now think that the core of self-regulated teacher learning is best defined by: "independently directing the process of improving teaching and/or attaining learning goals".

Finally, we return to the three conceptions of how teachers learn put forward by Cochran-Smith and Lytle (1999). Our findings were quite different from what we expected based on those conceptions. Our teachers seldom participated in training, reading, or other types of study (see the first conception). They seldom reported that they were engaged in conscious en structured reflection in order to construct practical knowledge (see the second conception). None of the teachers wrote us about intentional (systematic) investigation (third conception). Based on the findings of our small scale study, we would like to add a potential fourth conception of how teachers learn.

In this fourth conception, it is recognized that there are several ways in which teachers regulate their learning experiences. Teachers learn by all kinds of day-to-day teaching experiences without planning this. For example, they spontaneously learn by taking note of remarks made by students or colleagues. They also learn in a non-linear way by solving problems. These processes might not be self-regulated in order to learn as such, but firstly regulate (their improvement of) their teaching practice. Besides this self-regulation of their teaching practice with learning as a result, teachers also deliberately set time aside for self-regulated learning experiences. With this description, the fourth conception may acknowledge the specific context of teacher learning processes at the workplace. 


\section{Further research}

There is clearly a need to verify the conclusions of the small scale qualitative study presented here. Future research could look into the processes of the non-linear learning, because this type of learning seems to connect with the learning of modern multimedia (think of surfing on the Internet). How are decisions made about what to learn or what to do in this learning process? What makes people quit non-linear learning: how do they decide that they have learned enough and that it is time to move on to a different subject? Future studies might take into account the two critiques as formulated by Webb (1997) considering the phenomenographic method. Basically Webbs' (1997) concerns relate to the 'prejudices' of phenomenographers as they construct and interpret categories of understanding (p. 200). According to Webb, categories are not just 'simply there' but are, when constructed, influenced by the historical and social experience of the researcher. In addition, one of these categories often displays the 'correct meaning' as judged by the researcher while the others "are recapitulations of earlier, now supposedly discredited accounts" (p. 201). Following Webb, it seems likely that phenomenographic researchers will tend to report the history of a discipline as it is understood by them instead of seeing new conceptions. In order to handle these critiques Webb suggests a more hermeneutic approach, in which a deeper understanding may be reached for example by involving the research participant in the conversation in which categorization and judgment takes place. This is in line with the solution given by Linder and Marshall (2003) to a similar problem. They plea for a) a frequent and deliberate 'shifting in focus,' while constructing the categories (p. 280), since there is a relation between the focus and meaning given to a certain object of learning, and b) a 'mindful searching for variation to explore an object of learning' (p. 282) in order to see what has not been seen before.

\section{Note}

1. To guarantee complete anonymity, we did not include the codes of the participants here.

\section{References}

Bolhuis, S.M. and Simons, P.R.J. (1999). Leren en werken. [Learning and working]. Alphen aan de Rijn: Samsom. 
Butler, D.L. (2003). Self-regulation and collaborative learning in teachers' professional development. Paper presented at the 2003 annual meetings of the European Association for Research in Learning and instruction (EARLI), Padua, Italy.

Calderhead, J. (1996). 'Teachers: Beliefs and knowledge', in Berliner, D.C. and Calfee, R.C. (eds.), Handbook of Educational Psychology. New York: MacMillan, pp. 709-725.

Candy, P.C. (1991). Self-direction for Lifelong Learning. A Comprehensive Guide to Theory and Practice. San Francisco: Jossey-Bass.

Cochran-Smith, M. and Lytle, S.L. (1999). 'Relationships of knowledge and practice: Teacher learning in communities', Review of Research in Education 24, 249-305.

Confessore, S.J. and Kops, W.J. (1998). 'Self-directed learning and the learning organization: Examining the connection between the individual and the learning environment', Human Resource Development Quarterly 9(4), 365-375.

Danes, C. and Tremplay, N. (1985). 'Critical analysis of adult learning principles from a self-directed learner's perspective'. Presented at the Annual Meeting of Adult Education Research, Tempe, U.S.A.

Darling- Hammond, I. (1997). 'School reform at the crossroads: Confronting the central issues of teaching', Educational Policy 11(2), 151-166.

Eraut, M., Alderton, J., Cole, G. and Senker, P. (1998). Development of Knowledge and Skills in Employment. Brighton: University of Sussex.

Francis, D. (1995). 'The reflective journal: A window to pre-service teachers' practical knowledge', Teaching and Teacher Education 11, 229-241.

Garcia, T. (1999). 'Maintaining the motivation to learn: An introduction to this special issue of learning and individual differences', Learning and Individual Differences 11(3), 231-232.

Guilfoyle, K., Hamilton, M.L. and Pinnegar, S. (1997). 'Obligations to unseen children', in Loughran, J. and Russell, T. (eds.), Teaching About Teaching. London: Falmer Press.

Hamilton, M.L. (1998). Reconceptualizing Teaching Practice; Self-study in Teacher Education. London: Falmer Press.

Hashweh, M.Z. (2003). 'Teacher accommodative change', Teaching and Teacher Education 19, 421-434.

Knight, P.T. (2002). 'Learning form schools', Higher Education 44, 283-298.

Kolb, D.A. (1984). Experiential Learning: Experience as a Source of Learning and Development. Englewood Cliffs, NY: Prentice-Hall.

Korthagen, F.A.J. and Kessels, J.P.A.M. (1999). 'Linking theory and practice: Changing the pedagogy of teacher education', Educational Researcher 28(4), 4-17.

Kwakman, K. (1999). Leren van docenten tijdens de beroepsloopbaan. Studies naar professionaliteit op de werkplek in het voortgezet onderwijs. [Teacher learning during the professional career. Studies to the professionalism at the workplace in secondary education]. Doctoral dissertation. Nijmegen University.

Linder. C. and Marshall. D. (2003). 'Reflection and phenomenography: towards theoretical and educational development possibilities', Learning and Instruction 13, 271-284.

Long, H.B. (1994). 'Resources related to overcoming resistance to self-direction in learning', in Hiemstra, R. and Brockett, R. (eds.), Overcoming Resistance to Self-directed Learning in Adult Learning. New Directions for Adult and Continuing Education, No. 64. San Francisco: Jossey-Bass. 
Marton, F. (1986). 'Phenomenography - A research approach to understanding different understandings of reality', Journal of Thought 21, 28-49.

Marton, F. (1990). 'The pheomenography of learning - a qualitative approach to educational research and some of its implications for didactics', in Mandl, H., De Corte, E., Bennett, S.N. and Friedrich, H.F. (eds.), Learning and Instruction-European Research in an International Context, Volume 2.1. Oxford: Pergamon Press, pp. 601-616.

Oosterheert, I.E. and Vermunt, J.D. (2001). 'Individual differences in learning to teach: Relating cognition, regulation and affect', Learning and Instruction 11(2), 133-156.

Oosterheert, I.E., Vermunt, J.D. and Denessen, E. (2002). 'Assessing orientations to learning to teach', British Journal of Educational Psychology 72, 41-64.

Oosterheert, I.E. and Vermunt, J.D. (2003). 'Knowledge construction in learning to teach: The role of dynamic sources. Teachers and Teaching: Theory and Practice 9, $157-163$.

Pajares, M.F. (1992). 'Teachers' beliefs and educational research: Cleaning up a messy construct', Review of Educational Research 62, 307-332.

Paris, S.G. and Paris, A.H. (2001). 'Classroom applications of research on self-regulated learning', Educational Psychologist 36(2), 89-101.

Pintrich, P.R. (1994). 'Continuities and discontinuities: future directions for research in educational psychology', Educational Psychologist 29, 137-148.

Renstrom, L., Anderssson, B. and Marton, F. (1990). 'Students' conceptions of matter', Journal of Educational Psychology 82, 555-569.

Schön, D.A. (1987). Educating the reflective practioner. San Francisco: Jossey-Bass.

Shuell, T.J. (1988). 'The role of the student in learning from instruction', Contemporary Educational Psychology 13, 276-295.

Simons, P.R.J. (1993). 'Constructive learning: the role of the learner', in Duffy, T.M., Lodewyck, J. and Jonassen, D.H. (eds.), Designing Environments for Constructive Learning. Berlin: Springer, pp. 291-313.

Spear, G.E., and Mocker, D.W. (1984). 'The organizing circumstance. Environmental determinants in self directed learning', Adult Education Quarterly 35, 1-10.

Tillema, H.H. (2000). 'Belief change towards self-directed learning in student teachers: Immersion in practice or reflection on action', Teaching and Teacher Education 16, $575-591$.

Tillema, H.H., Kremer-Hayon, L. (2002). 'Practice what we preach- teacher educators' dilemmas in promoting self-regulated learning: a cross case comparison', Teacher and Teacher Education 18, 593-607.

Tough, A. (1979). The Adult Learning Projects (2nd edn.). Toronto: OISE.

Van Hout-Wolters, B., Simons, R.J. and Volet, S. (2000). 'Active learning: Self-directed learning and independent work', in Simons, R.J. et al. (eds.), New Learning. Netherlands: Kluwer Academic Publishers, pp. 21-36.

Verloop, N. (2001). 'Guest editors introduction', International Journal of Educational Research 35, 435-440.

Vermunt, J.D. (1996). 'Metacognitive, cognitive and affective aspects of learning styles and strategies: A phenomenographic analysis', Higher Education 31, 25-50.

Vermunt, J.D. (1998). 'The regulation of constructive learning processes', British Journal of Educational Psychology 68, 149-171.

Vermunt, J.D. and Verloop, N. (1999). 'Congruence and friction between learning and teaching', Learning and Instruction 9, 257-280. 
Webb, G. (1997). 'Deconstructing deep and surface: Towards a critique of phenomenography', Higher Education 22, 195-212.

Winne, P.H. and Perry, N.E. (2000). 'Measuring self-regulated learning', in Boekaerts, M., Pintrich P.R. and Zeidner, M. (eds.), Handbook of Self-regulation. San Diego, CA: Academic Press, pp. 531-566.

Zimmerman, B.J. (2000). 'Attainment of self-regulation: A social cognitive perspective', in Boekaerts, M., Pintrich P.R. and Zeidner, M. (eds.), Handbook of Self-regulation. San Diego, CA: Academic Press, pp. 13-39.

Zimmerman, B.J. and Schunk, D.H. (2001). Self-regulated learning and academic achievement; theoretical perspectives. Mahwah, New Jersey: Lawrence Erlbaum Associates.

Zimmerman, B.J. (2002). 'Becoming a self-regulated learner: an overview', Theory into Practice 21(2), 64-70. 